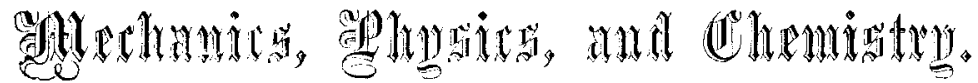

\section{ANALYSIS OF HOT CAST PORCELAIN WITH SOME REMARKS ON ITS COMPOSITION,}

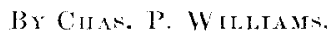

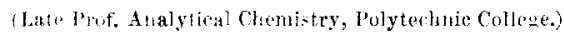

"Hor Cast Porcelain" is the trade-name of a peculiar, tough, milk-white, translucent glass, not unlike French porcelain in appearance, now extensively manufactured in Philadelphia and Pittsburg. It is intermediate in character with the glasses produced by the addition of phosplate of lime to the ordinary glass materials, on the one hand, and the white enamels, such as are produced by oxide of tin, on the other, having more of the milkiness than the former, and less opacity than the latter.

The raw materials consumed in its production are sand, oxide of zinc and cryolite (native double fluoride of aluminium and sodium) which are melted together in the ordinary clay pots of the glass maker. After complete fluxing, and when in a state of quiescent fusion, the material or "metal" is capable of all the manipulations of the ordinary glasses.

The following is the composition of an average sample of this glass, taken when the "metal" was in its best working condition: Silicic acid, $63 \cdot 84$; alumina, 7.86 ; sesquioxide iron, 1.50 ; protoxide manganese, 1.12 ; oxide zinc, 6.99 ; lime, 1.86 ; magnesia, 0.25 ; soda, 10.51; fluorine, 8.05 ; [less oxygen (corresponding to the fluorine) 3.39$]=98.59$. The above is the mean of five analyses by my. self; two analyses by $\mathrm{Mr}$. Wm. Main, Jr., in my laboratory give a mean agreeing very closely with that given above.

The method pursued in the above analyses consisted in fusing the compound with carbonate of soda, extracting with water, and, after precipitating the silica and alumina in the aqueous solution by means of carbonate ammonia, separating the fluorine as fluoride calcium, mixed with carbonate of lime, by the addition of chloride of calcium. The mixed salts were afterwards treated with acetic acid, and the separated fluoride of calcium, dried, burned and weighed. The remainder of the analyses was conducted as is usual in the analysis of silicates, the alumina and oxide of iron being precipi. tated as basic acetates and separated, after weighing, by means of 
tartaric acid and sulphide anmonium: the oxide of manganese precipitate as binoxide in the acetic acid solution, by means of bromine; $*$ the zine precipitated as a sulphicle by sulphydric acid in presence of acetic acid, and weighed either as a sulphide (by ignition with sulphur in a current of hydrogen gas) or as an oxide; the lime thrown down as an oxalate and weighed as caustic lime, and the magnesia precipitated by phosphate soda. Separate portions were taken for the alkali determinations and treated with fluohydric acid in the usual way.

Admitting the fluorine to exist in the glass in the condition of the silico-fluoride of sodium ( $\mathrm{Na} \mathrm{F} \mathrm{SiF}_{2}$ ), the following will express the composition of the compound:

\begin{tabular}{|c|c|c|c|c|c|}
\hline \multicolumn{2}{|c|}{ Per cent. } & \multicolumn{4}{|c|}{............... Oxygen } \\
\hline Alumina............. & $7 \cdot 86$ & ................. & 4 & $3 \cdot 66\}$ & \\
\hline Sesquioxide iron... & $1 \cdot 50$ & ................. & " & $.45\}$ & $4 \cdot 11-K_{2} O_{3}$ \\
\hline Protoxide mang.... & $1 \cdot 12$ & ................. & “" & $\cdot 25)$ & \\
\hline Oxide zine ........... & $6 \cdot 99$ & …............. & “" & $1 \cdot 38$ & \\
\hline Lime .................... & 1.86 & ................. & ؛ & .53 & $3.85-\mathrm{RO}$ \\
\hline Magnesia ............ & .25 & ................. & " & $\cdot 10$ & \\
\hline Soda.................. & $6 \cdot 18$ & ............... & " & 1.59 & \\
\hline Sodium................. & $3 \cdot 25$ & & & & \\
\hline Silicon ................ & $1.98\}$ & $\approx=13.28$ per & cent. Sil & ico-fluor & ride sodium. \\
\hline Fluorine............. & 8.05 & & & & \\
\hline
\end{tabular}

Which agrees very closely with the formula-

$$
2\left(\mathrm{R}_{2} \mathrm{O}_{3} 3 \mathrm{SiO}_{2}+3\left(\mathrm{RO}_{3} \mathrm{SiO}_{2}\right)\right)+\mathrm{NaF} \mathrm{SiF}_{2} \text {. }
$$

The protoxide of manganese results from the addition of binoxide to the materials for the purpose of destroying the color from the iron in the sand, etc. The total amourt of soda (10.51 per cent.) corresponds to $23.8 \pm$ per cent. of cryolite in the original mixture, which would contain 12.92 of fluorine, showing, therefore, that 4.87 , or about 39 per cent. of the whole amount of fluorine is eliminated, by the melting operation in the form of fluoride silicon $\left(\mathrm{SiF}_{2}\right)$, requiring for its formation 3.85 per cent. additional of silica.

These figures would give as the approximate composition of one

* I bave found the substitution of bromine for chlorine in the precipitation and separation of manganese to give very satisfactory results. It is particularly adapted for small amounts of manganese as in the ordinary run of iron ores, especially if the iron and alumina have been separated as basic acetates. 
hundred parts of the original mixture when introduced into the melting pots, 67.19 parts of silica, 23.84 of cryolite and 8.97 of oxide of zinc. This, I believe, does not materially differ from the formula used in the practical operations at the factories in Kensington and West Philadelphia.

The rationale of the process appears to consist in the formation of a silico-fluoride of sodium from a part of the fluorine and sodium of the cryolite, the remainder of the fluorine uniting with silicon for the production of fluoride of silicon in which form it escapes from the pot. The remaining silica, uniting with oxide of zinc, the soda and alumina, resulting in the formation of a compound silicate not differing essentially (except in the substitution of oxide of zinc for lime or some other base commonly employed in glass manufacture) from some of the varieties of glass. Throughout this glass the fused silico-fluoride is distributed, acting in the same manner, though differing in the degree of its effect, as the phosphate of lime, so long employed for the production of milky glasses, for it has been shown by Brezelius that the alkaline-fluorides, in presence of silica, fuse at a bright red heat, without the evolution of fluoride of silicon, and pass, on cooling, into porcelain-like masses, ${ }^{*}$ in the same manner as does the bone phosphate of lime. +

Besides the beautiful white glass produced in this manner, an additional benefit is derived by the employment of cryolite, from the fact that this mineral furnishes to the manufacturer of glass a com. paratively cheap source of soda, dispensing with all the manipulations necessary to the production of soda ash either from cryolite or from common salt.

I am informed by W. J. Cheyney, Esq., of Philadelphia, the patentee of this new article of glass, that an article corresponding essentially in properties with "Hot Cast Porcelain," can be produced by the substitution of fluor-spar (fluoride of calcium) for cryolite. The milkiness in this case may probably be due to the formation of a corresponding silico-fluoride of calcium. I have verified this statement by melting together a mixture of feldspar, sand, fluor-spar and soda-ash, obtaining a product much resembling the genuine article. I have not yet been able to complete an analysis of this product.

* Gmelin's Chemistry, vol. iii., page 374, English edition.

$\dagger$ Ib. Page 192. According to Saussuer, the fusion takes place at $378^{\circ}$ Wedgewood. 
The "Hot Cast Porcelain" is capable of being colored by the metallic oxides usually employed in the manufacture of colored glasses, but the beautiful white of the body of the material heightens greatly the effect of these coloring matters. Both the white and the colored materials now find extensive employment in the manufacture of druggists' and perfumers' wares, pedestals for oil lamps, lamp shades, table ware and flooring tile. The patterns for this last are chaste, and the effect exceedingly pleasing. I am informed that in point of durability they are superior to the imported encaustic tiles.

It may be well to state that the action on the pots of the materials used in the manufacture of this glass, is no greater than obtains in the production of the other glasses. The pots used in Philadelphia are made from a mixture of German and Missouri clays, tempered with the baked material from old, broken pots.

Philadelphia, March 13th, 1869.

\section{FORMATION OF AN ARTIFICIAL SPECTRUM WITH A FRAUNHOFER LINE.}

By A. Wallener.

IF, by means of a Holtz machine, at a short distance, the rapid discharges of a Leyden jar of about 30 square centimes are passed into an ordinary Geissler tube, and if the tube is placed before the slit of a spectroscope, the spectrum of the gas which fills the tube is first seen. If the length of the discharge is increased a little, the sodium line immediately appears as in the case of induction currents, by heating the capillary part of the tube placed before the slit. With a proper length of spark the brilliancy of the sodium line far exceeds that of the spectrum of the gas. By further increasing the distance of the discharge, the calcium line is produced with such intensity that it cannot be seen to greater advantage by any way hitherto known. Finaliy, if the length of the spark is again augmented, the phenomenon changes, the light in the tube assumes a dazzling splendor, this luminous line forms a continuous brilliant spectrum in which the spectroscope reveals a completely black line instead of the sodium line; this, therefore, is a Fraunhofer line. If the tube is attentively examined after this experi- 